\title{
Aspects Concerning "Play" for the Promotion of Preschool Children with Severe Speech- and Language Impairment
}

\author{
Dieter Ullrich ${ }^{1, *,+}$ and Magret Marten ${ }^{2,+}$ \\ 1 Medical Practice Pediatrics/ENT, Wedemarkstrasse 87, Wedemark 30900, Germany \\ 2 Sprachheilkindergarten, An der Autobahn 2, Langenhagen 30851, Germany; MagretMarten@gmx.de \\ * Correspondence: dieter-ullrich@t-online.de; Tel.: +49-513-037-3787 \\ + These authors contributed equally to this work.
}

Academic Editor: James Albright

Received: 22 October 2015; Accepted: 18 February 2016; Published: 4 March 2016

\begin{abstract}
Speech and language abilities are of great importance for later participation in economical and social life. In Lower Saxony/Germany, severely speech-/language (SL) impaired children may obtain special treatment during preschool in a so-called "Sprachheilkindergarten" (STK), a kindergarten focusing on early SL therapy. Purpose: This work analyzes the role of play during SL-therapy at the STK and monitors the long-term development and success of SL-impaired children. Methods: Long-term development (up to 19 years) of 71 children, who were dismissed from a STK during 1993 and 2006, was investigated. Playing habits were observed in 21 children (male: $n=14$, female: $n=7$ ), who were treated at STK in the years $2011 / 2013$. The study was designed as a register study. Results: Approximately $75 \%$ of the children attend a regular school or complete a standard professional training after being treated at the STK. Upon admittance, $100 \%$ of the children had severe SL impairment, in addition $75 \%$ of the children exhibit deranged, not age-appropriate playing behavior. Additionally, children often show indication of social-emotional problems. At dismissal from the STK, the children show measurable improvement of SL and playing abilities due to SL therapy and educational measures. But according to the present study there were no close statistical relations between play- and SL development. Conclusion: Due to active promotion and therapy, many children achieve to improve their SL and playing abilities. The apparent independent improvement of these skills allows them to catch up with other children in their age group. Potentially, this is the crucial aspect for a child's long-term development as it profits from its peer group.
\end{abstract}

Keywords: speech-language development; preschool children; therapy-play; speech-language therapy

\section{Introduction}

Appropriate speech-language (SL) development is an essential requirement for integration and participation in social and economical aspects of communal life [1,2]. It is known that the societal and cultural environment, and thus, the circumstances during play, highly influence a child's advances in SL development [3-6]. However, in modern societies an increasing proportion of children exhibit deficits in their speech-language development. The proportion of children with speech and language deficits is variable within regions. Data reveals that in Germany $7 \%$ to $30 \%$ of children show SL-deficiencies [7], while this number is 3\% to $35 \%$ in the United States [8].

Due to the great significance of speech and language, several countries provide various measures to appropriately promote speech-language-impaired children. The long-term effectiveness of these measures is evaluated very differently in literature. Evidence exists that these SL-promotion methods help affected children $[1,2,9,10]$. In addition, short- and medium-term follow-up examination indicate 
measurable benefits to the children after participation in SL-therapy that emphasizes practicing speech (McGinness, Padovan). However, other meta-analysis and studies do not confirm a long-term benefit for affected children due to SL therapy [11,12].

Speech and language deficits of affected children are often accompanied by the limitation of cognitive abilities, and additional behavioral and/or social-emotional problems.

\section{Background}

In the 1980s, early intervention in childhood education and targeted SL therapy for children with speech and language deficits was developed in the State of Lower Saxony, Germany based on empirical observations. The initial concept has not changed much to this day. It involved the treatment of children with SL deficits by enrolling them in specialized child care facilities (speech therapy kindergarten/STK) and, if required, primary schools with SL therapy integrated into their curriculum [13]. Eligible participants include mostly children with significant SL impairment or delay as well as other speech pathology such as stutter, verbal dys- and apraxia. Impairments of language and/or reading may include pronunciation, grammar, dyslexia and problems with phonological awareness, phonological decoding and orthographic coding, as well as difficulties with appropriate communication. Speech-language therapy is aimed at preschoolers aged 4 to 6 years. Admission to the specialized kindergartens is based on the assessments by a pediatrician and speech pathologist. These kindergartens were established as the majority of children with impaired language/speech skills experience a considerable negative effect on their later academic and psycho-social development $[1,2,14,15]$.

Prerequisites for admission to a kindergarten with targeted SL therapy include unsuccessful ambulant therapy sessions (some children received between 40 and 60 consultations with a speech therapist), exclusion from other major medical conditions and a medical SL-therapy assessment.

The provided therapy is based on the assumption that even severe SL impairment is treatable to such an extend that affected children can be educated at regular primary and secondary schools.

The ratio of children to childcare personnel is much lower in specialized speech therapy kindergartens compared to that of a standard kindergarten. As $85 \%$ of children with significant SL deficits have an additional delay in their cognitive and psycho-social development, a multidisciplinary approach is used for this specialized early childhood education. Supervision and education follows a multidisciplinary approach, involving childcare staff, speech therapists and physiotherapists, and psychologists in order to optimize the development of SL-skills, as well as cognitive, social, emotional and physical abilities.

The average duration of treatment in a speech therapy kindergarten ranges from 12 to 18 months. It is expected that children then transition to a standard primary or elementary school. However, some children attend a primary school with additional SL-therapy integrated into the curriculum.

The German education system can vary considerably from the Anglo-Saxon system. In Germany, kindergartens fulfill a preschool function, and are designed to allow social and academic development. At age 6 to 7, children attend primary school for four years. After completion of primary school, different types of regular secondary schools exist.

\section{Aim}

This study investigates the diagnostic and therapeutic techniques employed at the speech therapy kindergarten and analyzes the long-term development of SL-impaired children attending the STK. Many of these children suffer from severe speech deficits and cognitive inabilities with additional behavioral problems. Elements containing play are of crucial significance during therapy of children, aged 4 to 6 , who attend the specialized kindergarten. Thus, this study focuses on the importance of play during therapy and diagnostics of SL-impaired children. 


\section{Material and Methods}

Prior to inclusion in this study, all potential participants and their parents or legal guardians were consented for participation in the study. The study adheres to the Declaration of Helsinki (World Medical Association 1964; amended 2008 [16]).

During the years 1993 and 2012 a total of 427 children attended the investigated speech therapy kindergarten. The native tongue of the predominant majority of the children was German. The duration of attendance at the STK was 12 to 36 months with a median of 18 months. In 2011, a total of 71 of 227 enquired children, who had left the specialized kindergarten between the years 1993 and 2006, were retraced by mail questionnaires to evaluate their long-term development. A smaller group of the children was evaluated through personal questionnaires. In 2011, the median age of the participants was 14.5 years, ranging from 9 to 23 years. This study includes 54 males and 17 females [10].

Further findings of this study are based on case notes and test records on 21 children, who attended the STK in the years 2011 and 2013. Studies include 14 males and 7 females, aged between 4 and 5 years.

The evaluations were based on observation, psychological assessments, and standardized assessment methods by qualified staff members such as psychologists and childcare workers of the STK. The objective, formal assessment techniques included a variety of examinations and questionnaires, most of them clinically validated (Table 1 ).

Table 1. Examined skills, sources and test procedures.

\begin{tabular}{|c|c|c|}
\hline Skills & Sources & Test Procedure \\
\hline Language Skills & Examination & $\begin{array}{c}\text { SETK-3-5 Test for Speech Development of } \\
\text { children aged 3-5 years; validated [17]. } \\
\text { AWST-R_-Vocabulary test for children aged } \\
\text { 3-5 years; validated [18]. } \\
\text { TROG-D_-Grammar test; validated [19]. } \\
\text { HSET-Test for Speech Development } \\
\text { (Heidelberg); validated [20]. } \\
\text { Assessment of Paediatric phonetics and } \\
\text { pronunciation; not validated [21]. } \\
\text { Status speech-/language development, } \\
\text { not validated-Educator. }\end{array}$ \\
\hline
\end{tabular}

\begin{tabular}{cc}
\hline Number of siblings & Questionnaire, case files \\
\hline Family Income & Questionnaire \\
\hline Duration of STK attendance & Questionnaire \\
\hline
\end{tabular}

SON-R; validated [22].

IQ Examination HAWIWA III; validated [23].

CFT1; validated [24].

Der Mann-Zeichen-Test; validated [25].

\begin{tabular}{|c|c|c|}
\hline Self-confidence & Examination & \\
\hline Focus/Concentration & Examination & \\
\hline Auditory Perception & Examination & \\
\hline Visual perception & Examination & $\begin{array}{l}\text { FEW-2: Frostig Test for Assessment of } \\
\text { Visual Perception; validated [26]. }\end{array}$ \\
\hline Ideas at crafts/construction & Examination & \\
\hline Gross motor skills & Examination & $\begin{array}{l}\text { MOT 4-6: Evaluation of Motor skills for } \\
\text { children aged 4-6 years; validated [27]. }\end{array}$ \\
\hline
\end{tabular}

In principle, formalized testing procedures are performed prior to admission to the speech therapy kindergarten. Depending on the duration of the child's stay at the STK, the assessment is 
repeated after 12 and 18 months, respectively. However, a majority of the children is incapable of accomplishing formalized test procedures upon admission to the STK, due to SL-deficits, cognitive limitations, and social-emotional problems.

The selection of 21 children for individual analysis was carried out in alphabetical order. Three trained individuals independently evaluated files and data of all examined children. In the case of discrepancies in the analysis, a joint assessment was performed. For this study, the analysis of diagnostics and therapy relies on standardized testing procedures, such as Status Speech/Language Development, AWST, TROG D and PDSS (Table 1).

In STK the ratio childcare workers to SL-impaired children is 1.5:8. Play is the most important tool in STK to achieve educational goals. These goals include a certain degree of independence, verbal communication skills, social behavior, basic cognitive competencies, such as identifying small quantities or colors, and the development of motor functions. In group sessions abilities including play are trained and children are allowed to interact with each other. Personal skills are developed during individual lessons with speech therapists. Each child has its personalized weekly schedule with various educational sessions and proposals. Its progress is evaluated four times a year by speech therapist, educationist and psychologist. These different evaluations are summarized and documented in formalized case notes. Approximately $50 \%$ of the content of case notes refer to speech-language (approximately 320 items), 25\% to play- and social behavior and the remaining $25 \%$ to motor development, auditive dysfunction and educational recommendations. In principle, the expressed percentages allow an estimate of the impact of the various educational measures.

To illustrate the playing behavior of the examined children $[8,28,29]$, some important attributes from the case notes were evaluated with " 0 " and " 1 " and accumulated:

- The child plays alone vs. plays in a group and alone;

- During play the child shows limited interest $v s$. shows versatile interest;

- Planning of actions during play is insecure vs. confident;

- Social skills during play are marginal vs. age-appropriate;

- The child's frustration tolerance is low $v s$. adequate.

The accumulated points are in a range between 0 and 5 points and provide the basis to further analysis as a surrogate "play score rating" (Table 2). The listed criteria have been selected according to a handbook that describes the development of children in childcare facilities, named "Gelsenkirchener Entwicklungsbegleiter" [30], partially based on ICF-CY [31]. The assessment of individual children is based on subjective impression of the above mentioned staff members. Finally the various judgments are summarized to one opinion.

Table 2. "Play-Score Rating".

\begin{tabular}{ccc}
\hline Criteria & Not Age-Appropriate & Age-Appropriate \\
\hline Plays alone vs. Plays in Group and alone & 0 & 1 \\
During Play Limited Interest vs. Versatile Interests & 0 & 1 \\
Planning Actions Insecure vs. Confident & 0 & 1 \\
Social Skills Marginal vs Age-appropriate & 0 & 1 \\
Frustration Tolerance Low vs Adequate & 0 & 1 \\
TOTAL SCORE (Maximum 5) & \\
\hline
\end{tabular}

Notes: Play Score Rating: 0, 1, 2: Below “age appropriate"; 3: intermediate; 4, 5: "age appropriate".

Data obtained by observing children and their behavior such as play and other skills were documented in case notes. For statistical analysis of the present study the data from the case notes data were designed according to the criteria of a "Registry Study" [32]. Additional statistical analysis was performed using Microsoft Excel to analyze mean, standard deviation, median, range and calculate other basic statistics. 


\section{Results}

The prospective, longitudinal study in 2011 assesses 71 of 227 children, with a follow-up time between 5 to 19 years. Upon admission to the STK, children (approximately aged 4 years) show no or limited ability to communicate with SL. Discharge from the kindergarten occurred at a median 7.5 years prior to assessment (range $4-19$ years).

At the time of the final survey in 2011, $58(64 \%)$ children attended a secondary school: 44 of the 58 children attended a regular secondary school, $14(24 \%)$ children attended a secondary school for children with special needs. Thirteen of the children, that had originally attended the STK, continued with university education or professional training upon completion of their secondary schooling (Figure 1).

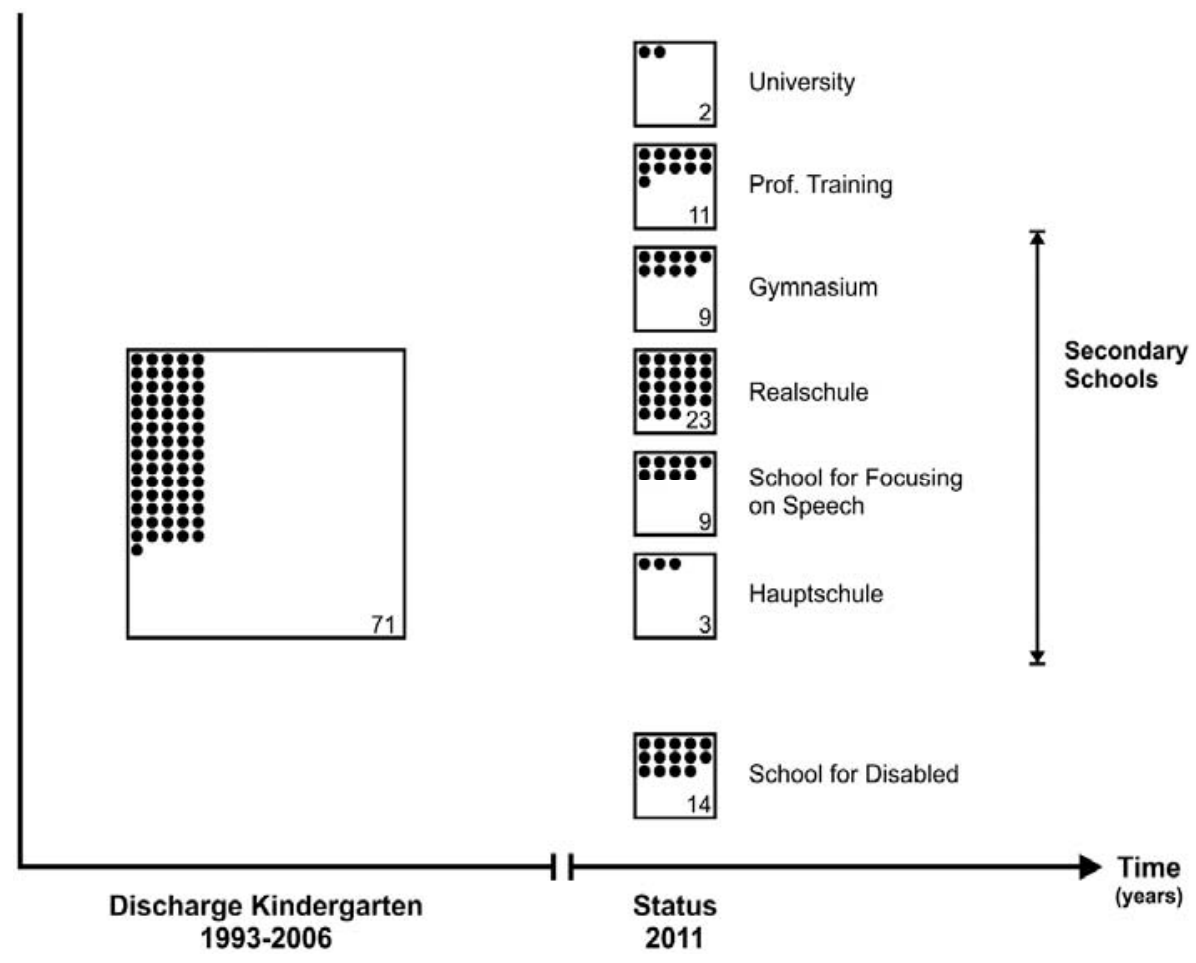

Figure 1. Educational long-term follow up of 71 children discharged from "Speech therapy kindergarten (STK)" between 1993 and 2006.

At the age of four, many children, who suffer from severe SL deficits, cognitive limitations, and/or behavioral problems, do not have the ability to accomplish formalized testing procedures, due to new and unknown conditions. The ability to be tested improves severely as soon as a positive attachment is established to an educator at the STK. Upon admission to the STK, children can only be evaluated utilizing social-emotional play-like methods, as illustrated in Figure 2. After a median time duration of three weeks the level of SL can be tested (method: Status SL), often involving play-like testing procedures. After 5.5 months (median) children can be subjected to a simple formalized test for reception of grammar (method: TROG D). After only 8 months (median) children can accomplish a complex and difficult active vocabulary test (method: AWST). The time, after which individual children can accomplish various testing procedures, varies considerably among single individuals, as depicted in Figure 2.

Upon admission to the speech therapy kindergarten, the median surrogate "play score ranking" for 20 individuals is " 2 ". After having left the STK, 7 of 14 children have improved their individual score to " 3 " or higher, while a decreased score was observed for one child. Figure 3 shows that upon admission to the SHK, 5 of 20 children exhibit age-appropriate playing behavior (score of 4 and 5). 
A total of 12 of 20 individuals perform age-appropriately (score 3 to 5) after leaving the STK. For one child case notes do not supply complete data concerning playing behavior.

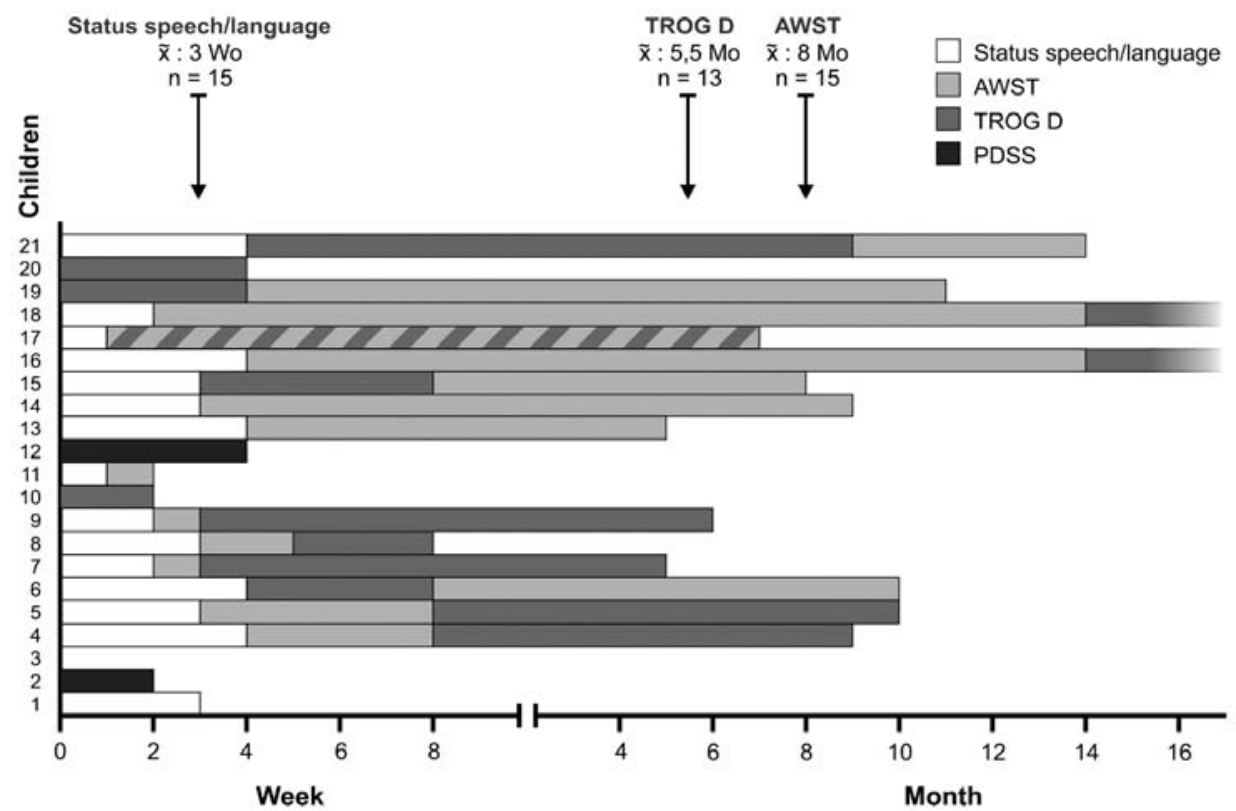

Figure 2. Time table depicting points when testing of various parameters in the single individuals was possible $(n=20)$. In the upper section median time points of various testing procedures are shown.

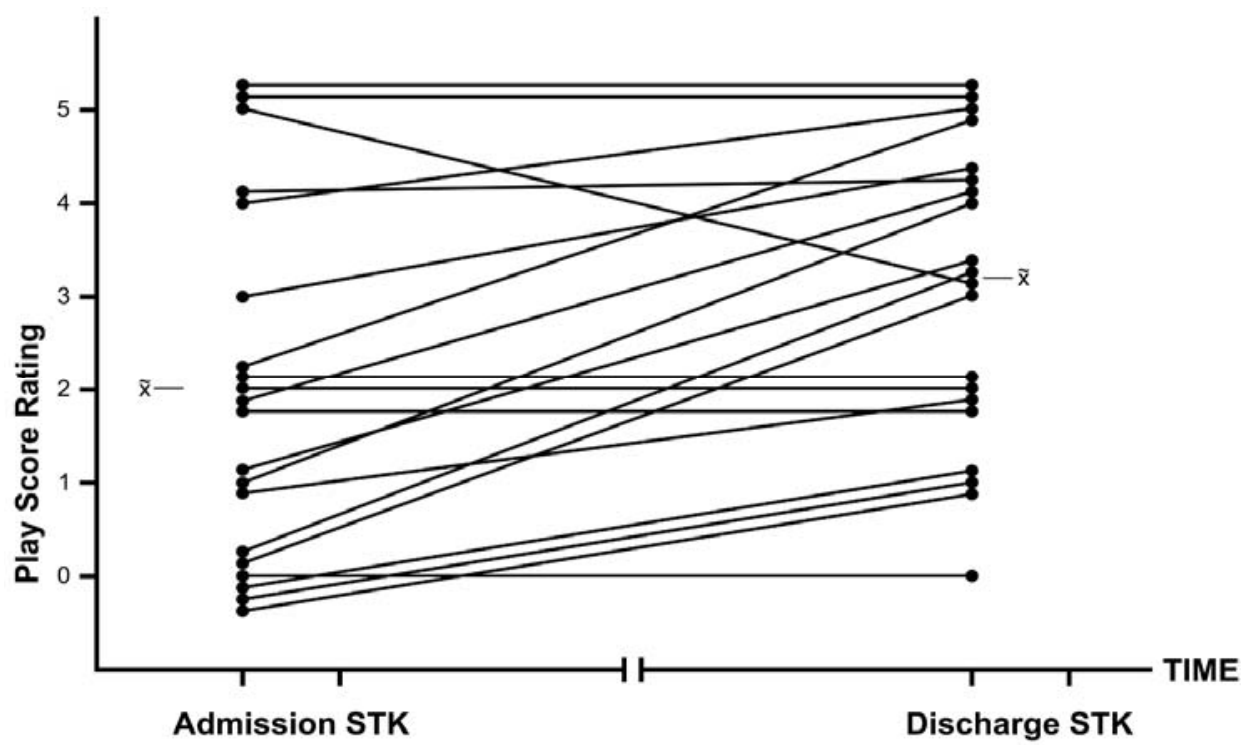

Figure 3. Individual development and means of "Play Score Ranking" in 20 children treated in STK; additional median-values are given.

Figure 4 illustrates the therapeutic SL-outcome for evaluated children based on the surrogate parameters clarity of spontaneous speech and vocabulary. Both parameters show a clear increase for children upon leaving the STK compared to the findings on admission. Thus the fraction of children with age-appropriate clarity of spontaneous speech increased from $19 \%$ at admission to $67 \%$ at dismissal, while the fractions for age-appropriate vocabulary were $10 \%$ and $57 \%$, respectively. 


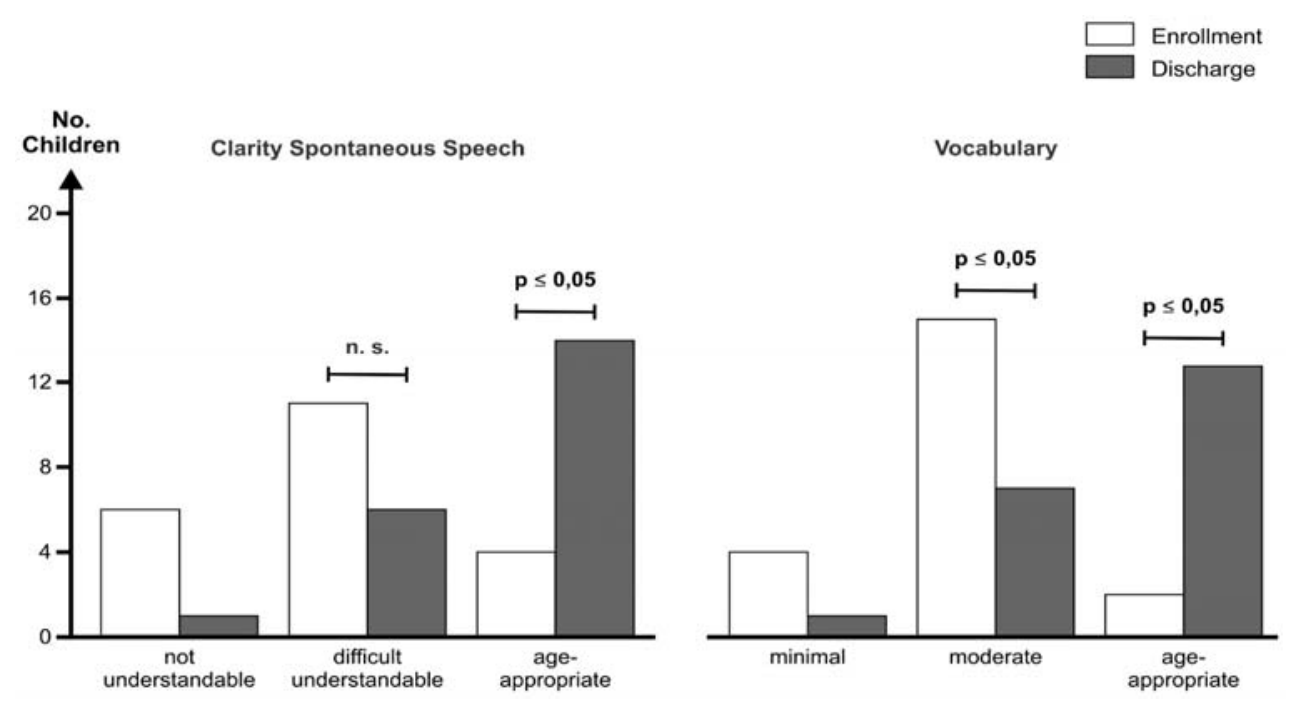

Figure 4. "Clarity of spontaneous speech" and "vocabulary" as surrogate parameters for SL development in 21 children from STK monitored at enrollment and dismissal.

To appropriately perform test procedures or to benefit from SL therapy lessons, tested children require some basic cognitive and emotional competencies, which they very often do not possess. Thus, at the beginning of therapy speech therapist must establish a close and confident relationship with the child, preferentially through play, before successful SL-teaching is possible.

In addition, during further therapy, play remains a helpful measure, as children are allowed to pursue their own interests and are not severely confronted with their linguistic limitations. Thus, the children's interest is increased and they experience joy of learning. In order to understand possible correlations between behavior during play and the SL-development, the results of the assessments at enrollment and at dismissal are analyzed and correlated. Figure 5 shows that no distinctive correlation between play behavior and SL-development can be found. As indicated by the quarterly assessments the progress in play- and SL-development are clearly found during the last third of a child's education at an STK.

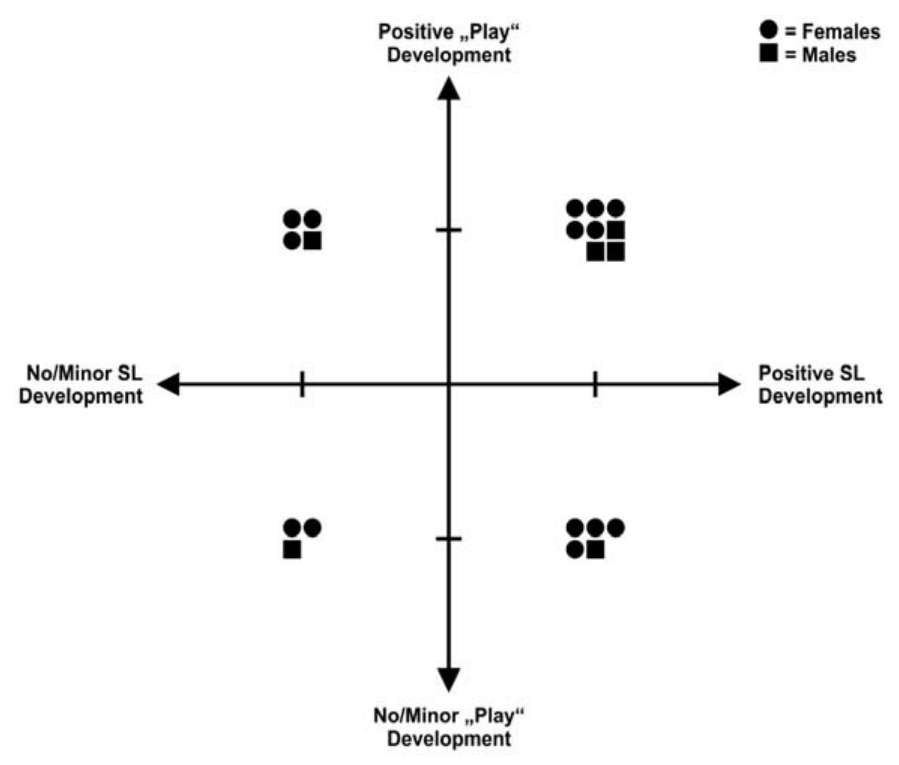

Figure 5. Development during educational period in STK and statistical relations of play and SL abilities in children $(n=21$; monitored at dismissal from STK). 


\section{Discussion}

Successful education of children is based on the promotion of social-emotional competencies, cognitive abilities, and SL-skills [14,33,34]. In Lower Saxony/Germany, appropriate therapeutic methods are applied to speech/language impaired, preschool children at specialized kindergartens for SL-therapy. Thus, the possibility exists to observe SL-development, cognitive skills, social-emotional abilities, and their interdependency on preschool children. The listed skills are often in close relation to the child's behavior during play.

The absence of a control group limits the present study. However, due to ethical reasons, it is not possible to conduct a control study in a German kindergarten. The study design corresponds to a Registry Study, which analyzes advantages and disadvantages of a method during an everyday situation retrospectively by means of individual case notes [32].

Long-term results of SL impaired children, who were treated early at a STK, are positive compared to those of later implemented therapeutic measures. Long-term observations show that $75 \%$ of children treated at a STK attend a regular school or complete professional training or apprenticeship [10]. Therapeutic success at early SL intervention during preschool corresponds to observations made by Heckman [2,34], Durkin et al. [33] and Miniscalco et al. [15].

Many of the children attending the STK at an age of approximately four years, exhibit severe SL-impairment. Thus, verbal communication is partly impossible, partly accompanied by strong difficulties. These children are increasingly challenged by additional behavioral deficits, such as social-emotional problems and cognitive difficulties. Hence, a substantial portion of children does not sufficiently tolerate the stress associated with standard testing methods after admission to the STK. Due to low stress tolerance, many children only conduct simple or play-oriented testing methods.

Consequently, in practice the results of various testing procedures upon admission to the STK are mainly based on observations made by therapists and preschool teachers. After establishing a meaningful relationship to a responsible pedagogue or therapist [35,36], and due to improvement of several skills, such as the ability to concentrate and stress tolerance [37], children are in a position to cope with more formalized and demanding testing methods. In the present study examples for these more standardized testing procedures are the AWST (Active-Vocabulary Test) or TROG D (Test for grammar). Although literature about infants is often ambiguous, our observations indicate a positive correlation between the nature of the attachment with a person of trust and the child's active exploration skills [38].

Activating explorational behavior not only includes abilities during testing procedure and speech, but also describes fundamental behavior during play [36]. Directly after enrollment at the STK, most children's play is not age-appropriate similar to behavior in test-procedures and /or SL impairment. In this study, only 5 of 20 children show playing behavior that is appropriate for their age upon admission to the STK. The other children (15 of 20), for example, lack the ability to play with others in a group. In other cases, children do not possess the skills to concentrate throughout a longer game, i.e., game rules are not understood or accepted $[28,29]$. Although diagnostics and therapy or promotion means cannot be clearly differentiated, typical difficulties arise from aforementioned problems during play. Diagnostic conclusions from observation of playing are possible only to a limited extend. In the context of therapy and promotion, non-age-appropriate playing behavior, such as an inability to play within a group, can cause children not to receive valuable stimuli and perspectives for their future development from their peer group [39]. Hence, Ervin-Tripp [40] claims that a child's peers induce the majority of its speech development, should be brought to perspective. In the authors' opinion this hypothesis is mainly valid in the case of a group of children with age-appropriate playing behavior.

Therapy at the STK aims to induce and develop age-appropriate abilities to learn and perform through goal-oriented and structured promotion of all aspects of a child's development. These means refer to SL-therapy, improvement of cognitive and social-emotional abilities and age appropriate play. As aforementioned analysis on a "play-score rating" illustrates, some children show improved playing 
behavior due to therapy. As soon as a child exhibits age-appropriate playing in a group with adequate frustration tolerance and the ability to concentrate, social and speech stimulating influences of the peer group can come into effect [41].

Based on the data available and the long experience in the field, the authors conclude that a combination of playful therapeutic and pedagogic measures improves an affected child's SL abilities as well as its social-emotional tolerance to stress. Therapy at the STK also facilitates play and improves these skills compared to the age group. The combination of all aforementioned measures has great influence on the children's development. In addition, according to our study, there is no direct relationship between play-development and SL-development. Although the number of examined children is small, this finding may indicate, that play, language and other attributes are (partially) independent skills, whose development is not synchronous. The positive long-term influence of the various means at STK on children may be based substantially on the fact that children are connected to their age-appropriate peer group, whereby they might profit increasingly from the interactions between the children [42].

\section{Conclusions}

Therapy at a specialized "Speech therapy kindergarten" can improve speech-/ language (SL) abilities of SL-impaired preschool children to a great extent. In later life approximately $75 \%$ of these children, who underwent therapy, attend regular schools and professional training successfully. Upon admittance to the specialized kindergarten many children suffer from additional deficiencies concerning their cognitive- and/ or playing abilities and/ or their social-emotional development. In the present study no immediate relation was found between play- and SL-development. But findings suggest that play is an important tool for diagnosis and therapy of SL-impaired children. Moreover play based methods can enhance the social-emotional stability of the children providing an important fundament for further SL-education.

Author Contributions: As a medical doctor and a pedagogue, both authors together are involved in the diagnosis and therapy of speech-/language impaired preschool children. The authors developed a hypothesis and conduct this study to overcome negative effects on SL-impaired children and improve future treatment strategies. This work addresses the problems that SL-impaired children may encounter and searches for the most effective therapy.

Conflicts of Interest: The authors declare no conflict of interest.

\section{Definitions}

Language The set of symbols (usually words or signs) which are organized by convention to communicate ideas.

Speech The physical production of language.

Articulation The physical movement of the mouth and throat involved in making the different speech sounds.

\section{References}

1. Glogowska, M.; Roulstone, S.; Peters, T.J.; Enderby, P. Early speech- and language-impaired children: Linguistic, literacy, and social outcomes. Dev. Med. Child Neurol. 2006, 48, 489-494. [CrossRef] [PubMed]

2. Heckman, J.J. Integrating Personality Psychology into Economics; NBER Working Paper No. 17378; National Bureau of Economic Research: Cambridge, MA, USA, 2011.

3. Bodrova, E. Make-believe play vs. academic skills: A Vygotskian approach to today's dilemma of early childhood education. Eur. Early Child. Educ. 2008, 16, 369-381.

4. Hoff, E.; Tian, C. Socioeconomic status and cultural influences on language. J. Commun. Disord. 2005, 38, 271-278. [CrossRef] [PubMed]

5. Hoff, E. How social context support and shape language development. Dev. Rev. 2006, 26, 55-88. [CrossRef]

6. Vygotsky, L.S. The Role of Play in Development. In Mind in Society; Cole, M., John-Steiner, V., Scribner, S., Souberman, E., Eds.; Harvard University Press: Cambridge, MA, USA, 1978 [1933]. 
7. von Suchodoletz, W. Sprech- und Sprachstörungen, Reihe: Leitfaden Kinder- und Jugendpsychotherapie; Hogrefe: Göttingen, Germany; Bern, Switzerland; Vienna, Austria, 2013; pp. 16-18.

8. Needlman, R. Growth and Development. In Nelson Textbook of Pediatrics, 15th ed.; Behrman, R., Kliegman, R., Arvin, A., Eds.; W.B. Saunders: London, UK; Toronto, ON, Canada; Philadelphia, PA, USA, 1996; pp. 30-72.

9. Gallagher, A.L.; Chiat, S. Evaluation of speech and language therapy interventions for pre-school children with specific language impairment: A comparison of outcomes following specialist intensive, nursery-based and no intervention. Int. J. Lang. Commun. Dis. 2009, 44, 616-638. [CrossRef] [PubMed]

10. Ullrich, D.; Ullrich, K.; Marten, M. A longitudinal assessment of early childhood education with integrated speech therapy for children with significant language impairment in Germany. Int. J. Lang. Commun. Dis. 2014, 49, 558-566. [CrossRef] [PubMed]

11. Law, J.; Boyle, J.; Harris, J.; Harkness, A.; Nye, C. Screening for speech and language delay: A systematic review of the literature. Health Technol. Assess. 1998, 2, 1-184. [CrossRef] [PubMed]

12. Wake, M.; Biostas, E.; Tobin, Sh.; Levickis, P.; Gold, L.; Ukoumunne, O.C.; Zenes, N.; Goldfeld, Sh.; Law, J.; Reilly, S. Randomized trial of a population-base, home-delivered Intervention for preschool language delay. Pediatrics 2013, 132, e895-e904. [CrossRef] [PubMed]

13. Flöther, M.; Schlüter, E.; Bruns, T. Interdisziplinaere Foerderung und Behandlung bei Hoer- und Sprachstoerungen-Ergebnisse zur Wirksamkeit eines Konzepts aus Niedersachen (Multidisciplinary assessment and management of children with hearing and language disorders-An assessment of the effectiveness of a concept from Lower Saxony, Germany). LOGOS Interdiszip. 2011, 19, 282-292.

14. Durkin, K.; Conti-Ramsden, G. Language, Social behavior, and the quality of friendships in adolescents with and without a history of specific language impairment. Child Dev. 2007, 78, 1441-1457. [CrossRef] [PubMed]

15. Miniscalco, C.; Hagberg, B.; Kadesjö, B.; Westerlund, M.; Gillberg, C. Narrative skills, cognitive profiles and neuropsychiatric disorders in 7-8-year-old children with late developing language. Int. J. Lang. Commun. Dis. 2007, 42, 665-681. [CrossRef] [PubMed]

16. World Medical Association. Declaration of Helsinki Ethical Principles of Medical Research Involving Human Subjects. 1964. Available online: http://www.wma.net/en/30publications/10policies/b3/ (accessed on 27 October 2010).

17. Grimm, H. SETK 3-5: Sprachentwicklungstest für 3-5 jährige Kinder; Hogrefe: Göttingen, Germany, 2001.

18. Kiese-Himmel, C. AWST-R: Aktiver Wortschatztest für 3-5 jährige Kinder; Hogrefe: Göttingen, Germany, 2005.

19. Fox, A. TROG-D: Test zur Überprüfung des Grammatikverständnisses, 5th ed.; Schulz-Kirchner-Verlag: Idstein, Germany, 2011.

20. Grimme, H.; Schöler, H. HSET_Heidelberger Sprachentwicklungstest; Hogrefe: Göttingen, Germany, 1991.

21. Hild, U. Bilderbuch zur Aussprachediagnostik bei Kindern; Orca GbR: Kassel, Germany, 2002.

22. Snijders-Oomen. Non-verbal Intelligence Test SON-R 21/2-7; Hild, P., Winkel, M., Wijnberg-Williams, B., Laros, J., Eds.; Swets \& Zeitlinger B.V.: Lisse, The Netherland, 1997.

23. Ricken, G.; Fritz, A.; Schuck, K.; Preuss, U. (Eds.) HAWIVA III-Hannover-Wechsler-Intelligenztest für das Vorschulalter III; Huber-Verlag/Hogrefe: Göttingen, Germany, 2007.

24. Cattell, R.; Weiss, R.; Osterland, J. CFT1: Grundintelligenztest Skala 1, 5th ed.; Hogrefe: Göttingen, Germany, 1997.

25. Ziler, H.; Brosat, H.; Tötemeyer, N. Der Mann-Zeichen-Test; Hogrefe: Göttingen, Germany, 2007.

26. Hammill, D.; Pearson, N.; Voress, J. Developmental Test of Visual Perception 2nd edit (DTVP-2); Hogrefe: Göttingen, Germany; Bern, Switzland; Vienna, Austria, 2007.

27. Zimmer, R.; Volkamer, M. MOT 4-6: Motoriktest für vier-bis sechsjährige Kinder, 2nd ed.; Verlag Weinheim: Landsberg, Germany, 1987.

28. Ayres, A.J.; Robbins, J. Sensory Integration and the Child; Western Psychological Services: Torrance, CA, USA, 1979.

29. Zollinger, B. Die Entdeckung der Sprache, 6th ed.; Haupt: Bern, Switzerland; Stuttgart, Germany, 2004.

30. Beyer, A.; Fastabend, S.; Liebers, E.; Per, G.; Schilling, M. Gelsenkirchener Entwicklungsbegleiter; DGVT Verlag: Tübingen, Germany, 2004.

31. World Health Organization; ICF-CY. International Classification of Functioning, Disability and Health. Children $\mathcal{E}$ Youth Version (German Edition); Verlag Hans Huber: Bern, Switzerland, 2011.

32. Stark, N.J. CDG Whitepapers: Registry Studies: Why and How. Available online: http://clinicaldevice. typepad.com/cdg_whitepapers/2011/07/registry-studies-why-and-how.html (accessed on 7 January 2016). 
33. Durkin, K.; Simkin, Z.; Knox, E.; Conti-Ramsden, G. Specific language impairment and school outcomes. II: Educational context, student satisfaction, and post-compulsory progress. Int. J. Lang. Commun. Dis. 2009, 44, 36-55. [CrossRef] [PubMed]

34. Heckman, J.J. Investing in disadvantaged young children is an economically efficient policy. In Building the Economic Case for Investments in Preschool; Committee for Economic Development: New York, NY, USA, 2006.

35. Goldberg, S.; Grusec, J.E.; Jenkins, J.M. Confidence in protection: Arguments for a narrow definition of attachment. J. Fam. Psychol. 1999, 13, 475-483. [CrossRef]

36. Grossmann, K.; Grossmann, K.E. Bindungen—Das Gefüge Psychischer Sicherheit, 5th ed.; Klett-Cotta: Stuttgart, Germany, 2012.

37. Nader-Grosbois, N.; Vieillevoye, S. Variability of self-regulatory strategies in children with intellectual disability and typically developing children in pretended play situations. J. Intellect. Disabil. Res 2012, 56, 140-156. [CrossRef] [PubMed]

38. Achtergarde, S.; Müller, J.; Postert, Ch.; Wessing, I.; Mayer, A.; Romer, G. Der Zusammenhang von Bindungsmustern und der Entwicklung von Angstsymptomen im Kindes- und Jugendalter. (Attachment pattern and their relation to the development of anxiety symptoms in childhood and adolescence). Prax Kinderpsychol. Kinderpsychiatr. 2015, 64, 496-526. [CrossRef] [PubMed]

39. Stagnitti, K.; Bailey, A.; Stevenson, E.H.; Reynolds, E.; Kidd, E. An investigation into the effect of play based instruction on the development of play skills and oral langauge: A 6-month longitudinal study. J. Child Res. 2015, 5, 1-18.

40. Ervin-Tripp, S. Play in language development. In Play and the Social Context of Development in Early Care and Education; Scales, B., Almy, M., Nicolopoulou, A., Ervin-Tripp, S., Eds.; Teachers College, Columbia University: New York, NY, USA, 1991; pp. 84-97.

41. Trevarthen, C.; Aitken, K.J. Infant intersubjectivity: Research, theory, and clinical applications. J. Child Psychol. Psychiatry 2001, 42, 3-48. [CrossRef] [PubMed]

42. Uren, N.; Stagnitti, K. Pretend play, social competence and involvement in children aged 5-7 years: The concurrent validity of the Child-Initiated Pretend Play Assessment. Aust. Occup. Ther. J. 2009, 56, 33-40. [CrossRef] [PubMed] 